\title{
EDUCAÇÃO SUPERIOR BRASILEIRA E REESTRUTURAÇÃO PRODUTIVA: REFLEXOS NAS DCN DOS CURSOS DE ENGENHARIA
}

\author{
BRAZILIAN HIGHER EDUCATION AND PRODUCTIVE RESTRUCTURING: \\ REFLECTIONS IN THE DCN OF ENGINEERING COURSES
}

EDUCACIÓN SUPERIOR BRASILEÑA Y REESTRUCTURACIÓN PRODUCTIVA:
REFLEJOS EN LAS DCN DE LOS CURSOS DE INGENIERÍA

Luciléa Santos Ayres da Silva

Universidade Federal do Amapá - Brasil

Arthane Menezes Figueirêdo

Universidade Federal do Amapá - Brasil

\begin{abstract}
Resumo: O presente estudo tem como objetivo contextualizar a Educação Superior brasileira permeada por contradições inerentes às transformações provocadas pela reestruturação produtiva, bem como analisar os reflexos desse processo nas Diretrizes Curriculares Nacionais (DCN) dos Cursos de Engenharia. Nesse sentido, emerge como problema, o seguinte questionamento: Quais os impactos da reestruturação produtiva na reconfiguração da Educação Superior e como se configuram seus rebatimentos nas DCN dos Cursos de Engenharia? Para tanto, metodologicamente, trata-se de um estudo exploratório que utiliza a pesquisa bibliográfica e a análise documental. Conclui-se que a Educação Superior, serve como pano de fundo para camuflar a exploração e a subordinação do trabalhador ao novo sistema de produção. Infere-se ainda que as DCN voltadas a Engenharia contribuem para cimentar a matriz ideológica do neoliberalismo, tendo em vista que seus desenhos curriculares, acabam por estabelecer estreito vínculo com o setor produtivo e por corroborar com a formação aligeirada e fragmentada de um trabalhador cada vez mais explorado e preparado para se adaptar a novas situações.
\end{abstract}

Palavras-chave: Educação Superior. Diretrizes Curriculares Nacionais dos Cursos de Engenharia. Reestruturação produtiva.

\begin{abstract}
The present study aims to contextualize Brazilian Higher Education permeated by contradictions inherent in the transformations provoked by the productive restructuring, as well as to analyze the reflexes of this process in the National Curricular Guidelines (NCG) of the Engineering Courses. In this sense, the following question emerges as a problem: What are the impacts of productive restructuring on the reconfiguration of Higher Education and how do they shape their refutations in the NCG of the Engineering Courses? For this, methodologically, it is an exploratory study that uses the bibliographical research and the documentary analysis. We conclude that Higher Education serves as a backdrop to camouflage the exploitation and subordination of the worker to the new production system. It is also inferred that the Engineering-oriented DCNs contribute to cementing
\end{abstract}


the ideological matrix of neoliberalism, since its curricular designs end up establishing a close link with the productive sector and corroborating with the light and fragmented formation of a worker at a time more exploited and prepared to adapt to new situations.

Keywords: Higher education. National Curricular Guidelines for Engineering courses. Productive restructuring.

Resumen: El presente estudio tiene como objetivo contextualizar la Educación Superior brasileña permeada por contradicciones inherentes a las transformaciones provocadas por la reestructuración productiva, así como analizar los reflejos de ese proceso en las Directrices Curriculares Nacionales (DCN) de los Cursos de Ingeniería. En este sentido, surge como problema, el siguiente cuestionamiento: ¿Cuáles son los impactos de la reestructuración productiva en la reconfiguración de la Educación Superior y cómo se configuran sus rebajas en las DCN de los Cursos de Ingeniería? Para ello, metodológicamente, se trata de un estudio exploratorio que utiliza la investigación bibliográfica y el análisis documental. Se concluye que la Educación Superior, sirve como telón de fondo para camuflar la explotación y la subordinación del trabajador al nuevo sistema de producción. Se infiere que las DCN dirigidas a Ingeniería contribuyen a cimentar la matriz ideológica del neoliberalismo, teniendo en vista que sus diseños curriculares, acaban por establecer estrecho vínculo con el sector productivo y por corroborar con la formación aligerada y fragmentada de un trabajador cada vez más explorado y preparado para adaptarse a nuevas situaciones.

Palabras clave: Enseñanza superior. Directrices Curriculares Nacionales de los Cursos de Ingeniería. Reestructuración productiva.

\section{Considerações iniciais}

O presente estudo apresenta uma contextualização da Educação Superior brasileira inserida em uma conjuntura ampla e de totalidade, marcada por contradições inerentes às transformações vivenciadas na reestruturação produtiva e, consequentemente, no mundo do trabalho e seus reflexos nas Diretrizes Curriculares Nacionais (DCN) dos cursos de Engenharia do Brasil. A formação do trabalhador e as exigências de novas qualificações devem ser compreendidas face ao processo de reorganização do modo de produção capitalista. Nesse sentido, propõe-se a problematizar e discutir, no contexto brasileiro, a seguinte questão: quais os impactos da reestruturação produtiva na reconfiguração da Educação Superior brasileira e como se configuram seus rebatimentos nas DCN dos cursos de Engenharia?

No tocante à metodologia adotada, este artigo possui cunho eminentemente exploratório, posto que, conforme Gil (2007, p. 27), visa “[...] proporcionar visão geral, de tipo aproximativo, acerca de determinado fato", buscando uma melhor aproximação e familiaridade com o tema trabalhado. Ademais, pautado na abordagem qualitativa, utiliza a pesquisa bibliográfica e a análise documental, uma vez que o documento escrito frequentemente representa "a quase totalidade dos vestígios da atividade humana em 
determinadas épocas. Além disso, [...] permanece como o único testemunho de atividades particulares ocorridas num passado recente" (CELLARD, 2012), de modo a perscrutar uma melhor compreensão do objeto em tela, para além da mera leitura e descrição do Parecer CNE/CES n. 776/97 e da Resolução CNE/CES n. 11/2002, que versam, respectivamente, sobre as orientações das diretrizes curriculares dos cursos de graduação, em geral, e, as DCN da área de Engenharia, em particular.

Está estruturado em três seções, além desta parte introdutória e das considerações finais. A primeira, "A crise estrutural do capitalismo: uma breve incursão", aborda as mediações estabelecidas no processo de reestruturação produtiva, intensificado nos anos 1970, com o mundo do trabalho. A segunda, “A Educação Superior brasileira sob a égide da nova ordem econômica e do princípio da flexibilização", apresenta as implicações da nova fase do capitalismo na formação de um novo perfil profissional e na reconfiguração da educação superior. E, a terceira, "As DCN dos cursos de Engenharia: materialização das mudanças curriculares", trata especificamente sobre a aproximação dos desenhos curriculares à esfera produtiva.

Dessa forma, este estudo pretende evidenciar que o ideário neoliberal, em meio a reestruturação do modo de produção do capital, promove o solapamento dos direitos sociais, dentre os quais percebemos a educação, e em particular a Educação Superior, ora afinada ao viés mercadológico do capital.

\section{A crise estrutural do capitalismo: uma breve incursão}

Oriunda do latim tripalium ou tripalus, o termo trabalho na sua acepção etimológica relaciona-se a um instrumento utilizado para subjugar os animais e forçar os escravos a aumentar a produção. Entretanto, de acordo com o pensamento marxista,

O trabalho é, antes de tudo, um processo entre o homem e a natureza, processo este em que o homem com sua própria ação, medeia, regula e controla seu metabolismo com a natureza. Ele se confronta com a matéria natural como uma potência natural [Naturmacht]. A fim de se apropriar da matéria natural de uma forma útil para sua própria vida, ele põe em movimento as forças naturais pertencentes a sua corporeidade: seus braços e pernas, cabeça e mãos. Agindo sobre a natureza externa e modificando-a por meio desse movimento, ele modifica, ao mesmo tempo, sua própria natureza. (MARX, 2013, p. 326-327).

Consiste, dessa forma, em uma atividade ontológica, inerente a essência humana, uma vez que por meio do trabalho o ser humano transforma a natureza, e modifica também a si 
mesmo, para satisfazer as suas necessidades vitais e interesses pessoais, por meio de ações intencionais. O trabalho é, portanto, resultado de mediações entre o homem e a natureza, caracterizado pela consciência, pela técnica e pela socialidade (ALVES, 2007). Assim, com essa ação intencional e consciente, o homem distingue-se das outras espécies animais e constitui-se como um ser social, produzindo sua própria condição material de vida e estabelecendo relações sociais.

Nas sociedades primitivas, o trabalho era considerado um meio de subsistência; na Antiguidade era função atribuída aos escravos; na Idade Média, aos servos; e, na sociedade do capital, aos trabalhadores, perdendo "seu sentido como processo de humanização, sendo incorporado como atividade natural de produção para a troca, independente do seu contexto histórico" (BEHRING; BOSCHETTI, 2008, p. 50), posto que o modo de produção capitalista possui seu alicerce na exploração da força do trabalho e a obtenção das taxas de lucros representa a sua força motriz.

Sendo assim, as relações capitalistas provocam profundas modificações no significado do trabalho. Inserido nesse contexto, buscando atender os objetivos do capital, a organização do modelo de produção predominante no século XX constitui-se a partir do binômio taylorismo/fordismo, consistindo em uma linha rígida de produção que

[...] articulava os diferentes trabalhos, tecendo vínculos entre as ações individuais das quais a esteira fazia as interligações, dando o tempo e o ritmo necessários para a realização das tarefas. Esse processo produtivo caracterizou-se, portanto, pela mescla da produção em série fordista com o cronômetro taylorista, além da vigência de uma separação nítida entre elaboração e execução. Para o capital, tratava-se de apropriar-se do savoirfaire do trabalho, 'suprimindo' a dimensão intelectual do trabalho operário, que era transferida para as esferas da gerência científica. A atividade de trabalho reduzia-se a uma ação mecânica e repetitiva. (ANTUNES, 2009, p. 39).

Tal sistema agregava o cronômetro taylorista e a produção em série fordista com vistas ao aumento da produção e dos lucros das indústrias, por meio da otimização do tempo e do ritmo de trabalho, baseando-se na produção de mercadorias em massa, no trabalho parcelado e fragmentado, bem como na segregação de atividades de gerenciamento e execução. $\mathrm{O}$ trabalho, ora mecanizado e repetitivo, não visava a exploração da capacidade intelectual e/ou cognitiva do trabalhador.

Frigotto (2000, p. 64) chama atenção para o "caráter contraditório do capitalismo, que o leva a crises periódicas e a ciclos abruptos e violentos”. Por sua vez, Mészáros (2000, p. 14) acrescenta que "a crise estrutural do capital é a séria manifestação do encontro do sistema 
com seus próprios limites". Desse modo, a década de 1970, período marcado por profunda recessão econômica, em uma combinação de baixas taxas de crescimento e altas taxas de inflação, inaugura uma fase de crise estrutural.

Antunes (2009) destaca os motivos mais evidentes dessa crise, tais como: a queda da lucratividade em função do aumento do valor da força de trabalho, provenientes das lutas sociais empreendidas nos anos 1960; o esgotamento do modo de produção taylorista/fordista; a hipertrofia da esfera financeira, na qual o capital financeiro fixa-se como campo de especulação no processo de internacionalização; a concentração de capitais oriundas das fusões de empresas monopolistas e oligopolistas; a crise do Welfare State (Estado de bemestar social), provocando a crise fiscal do Estado, restringindo os gastos públicos e transferindo suas responsabilidades para o capital privado; além das privatizações, desregulamentações e flexibilização do processo produtivo.

Dessa forma, como estratégia de enfrentamento da crise e com vistas a recuperação do processo de acumulação de capital, a classe burguesa, iniciou

[...] um processo de reorganização do capital e de seu sistema ideológico e político de denominação, cujos contornos mais evidentes foram o advento do neoliberalismo, com a privatização do Estado, a desregulamentação dos direitos do trabalho e a desmontagem do setor produtivo estatal, da qual a era Thatcher-Reagan foi a expressão mais forte; a isso se seguiu também um intenso processo de reestruturação da produção e do trabalho, com vistas a dotar o capital do instrumental necessário para tentar repor os patamares de expansão anteriores. (ANTUNES, 2009, p. 33).

Nessa conjuntura, o modelo fordista/taylorista é substituído paulatinamente pelo modelo japonês, denominado toyotismo, um modo de produção que combina o avanço tecnológico e o trabalho humano. Behring (2003) esclarece que,

Nessa nova forma produtiva, forja-se a articulação entre a descentralização produtiva e avanço tecnológico por meio da rede de microeletrônica de informações. Contrapondo-se à verticalização fordista, a produção flexível é, em geral, horizontalizada/descentralizada. Trata-se de terceirizar e subcontratar uma rede de pequenas e médias empresas, muitas vezes até com perfil semi-artesanal e familiar. A produção é conduzida pela demanda e sustenta-se na existência do estoque mínimo. O just in time e o kaban asseguram o controle de qualidade e o estoque. Um pequeno grupo de trabalhadores multifuncionais ou polivalentes opera a ilha de máquinas automatizadas, num processo de trabalho intensificado, que diminui ainda mais a porosidade no trabalho e o desperdício. (BEHRING, 2003, p. 35).

Refere-se, portanto, a uma nova organização da produção e do trabalho baseada nas seguintes características: atendimento a nichos de mercado; produção flexível com o uso da 
microeletrônica; trabalho em equipe; sistema just in time, com a produção de mercadorias no momento certo, visando a eliminação de desperdícios; e, sistema kaban, cartão utilizado para o controle da produção (ANTUNES, 2009).

Cabe destacar que, amparada no avanço tecnológico, essa nova forma de acumulação flexível implica em uma nova forma de organização industrial e de relacionamento entre capital e trabalho, provocando uma redução no contingente de trabalhadores e o aumento do desemprego estrutural, sendo este de extrema importância para a manutenção do modo de produção capitalista, na medida em que a composição de um exército de reserva possibilita a intensificação da exploração da força de trabalho.

Nessa esteira, situa-se a emergência do projeto neoliberal como reação econômica, teórica, política e ideológica, cujas políticas

[...] comportam algumas orientações que se combinam, tendo em vista a inserção de um País na dinâmica do capitalismo contemporâneo, marcada pela busca da rentabilidade do capital por meio de reestruturação produtiva e da mundialização: atratividade, adaptação, flexibilidade e competitividade. (BEHRING, 2003, p. 59).

Assim, visando garantir a recomposição do ciclo produtivo do capital, agora sob a predominância financeira, constata-se que tal lógica circunda a transformação dos processos produtivos, bem como a consequente flexibilização das atividades laborais e a emergência de um novo perfil de trabalhador, com implicações diretas na reconfiguração da Educação Superior, como observa-se nas análises a seguir.

\section{A educação superior brasileira sob a égide da nova ordem econômica e do princípio da flexibilização}

Conforme já demonstrado, o novo paradigma produtivo, alicerçado no avanço tecnológico e no modo de acumulação flexível, carrega em seu bojo uma nova relação capitaltrabalho, fundamentada no toyotismo, que "tende a exigir, para o seu desenvolvimento como nova lógica da produção capitalista, novas qualificações do trabalho que articulam habilidades cognitivas e habilidades comportamentais" (ALVES, 2007, p. 248).

Dentre tais qualificações, o trabalhador deve possuir criatividade, capacidade de tomar decisões, além de estar apto ao gerenciamento de processos e ao trabalho em equipe, tendo em vista que o processo de produção e reprodução do capital implica em uma nova lógica que agrega o conhecimento do trabalhador sobre a produção. 
Por conseguinte, engendrado pela revolução científico-tecnológica, o conhecimento assume papel central no processo produtivo, constituindo a denominada "sociedade do conhecimento/informação”. Burch (2005) esclarece que este conceito surgiu nos anos 1970, mantendo relação estreita com a tecnologia, sendo apropriado pelo neoliberalismo como recurso ideológico, em meados da década de 1990, para fundamentar o processo de desenvolvimento da mundialização do capital financeiro, no contexto da globalização.

Sobre esse aspecto, Neves e Pronko (2008), complementam afirmando que, a ideologia subjacente à "sociedade da informação/conhecimento",

[...] se firma na ocultação das relações sociais concretas nas quais esse conhecimento/informação se produz, se processa e se distribui, dissimulando a verdadeira natureza do modelo idealizado e proposto. [...] a dissimulação básica está em tratar conhecimento e informação como se fossem sinônimos, o que implica redefinir sociedade do conhecimento em sociedade da informação, sendo que a informação dispensa o trabalho reflexivo que transformaria os conteúdos do mundo exterior em verdadeiros conhecimentos. De fato, a utilização de ambos os conceitos de forma intercambiável e, muitas vezes, equivalente não faz mais do que retratar a atrofia de uma noção de conhecimento cada vez mais ligada a sua utilização diretamente produtiva a serviço da valorização do capital, sob o comando da finança mundializada. (NEVES; PRONKO, 2008, p. 147-148).

Não obstante, ao longo da história, o conhecimento cientifico e técnico sempre teve sua importância reconhecida, entretanto, ao apropriar-se da expressão conhecimento com sentido aproximado de informação revela aqui a sua feição ideológica, na medida em que mascara o seu viés pragmático e utilitarista, em busca de

[...] uma renovação de interesse e de ênfase, já que, num mundo de rápidas mudanças de gostos e necessidades e de sistemas de produção flexíveis (em oposição ao mundo relativamente estável do fordismo padronizado), o conhecimento da última técnica, do mais novo produto, da mais recente descoberta científica, implica a possibilidade de alcançar uma importante vantagem competitiva. O próprio saber se torna uma mercadoria-chave, a ser produzida e vendida a quem pagar mais, sob condições que são elas mesmas cada vez mais organizadas em bases competitivas. (HARVEY, 1992, p.51).

O conhecimento é, então, apreendido como uma mercadoria passível de comercialização. A educação, nesse contexto, "redefine seu perfil reprodutor/inovador da sociabilidade humana. Adapta-se aos modos de formação técnica e comportamental adequados à produção e à reprodução das formas particulares de organização do trabalho e da vida" (SHIROMA; MORAES; EVANGELISTA, 2007, p. 9). E, perante a nova lógica do 
capital, revitaliza a Teoria do Capital Humano ${ }^{1}$, difundida nos anos 1960 por Theodore Schultz, ao preconizar a formação de recursos humanos como estratagema para o desenvolvimento econômico e para a inserção no mercado de trabalho.

Bianchetti (1997) ratifica que essa teoria fundamenta-se na lógica do mercado e reduz a função da educação à formação de "recursos humanos" para a manutenção do sistema produtivo, subordinando o sistema educacional às demandas do modo de produção e, consequentemente, autenticando a consolidação da reprodução do capital.

A Teoria do Capital Humano carrega em seu bojo conceitos inerentes ao modelo de acumulação flexível, tais como: qualidade total, flexibilidade, autonomia e empregabilidade. Este último adquiriu centralidade a partir dos anos de 1990, constituindo-se como sustentáculo de um conjunto de políticas voltadas para a minoração dos riscos sociais da grande mazela da sociedade contemporânea, o desemprego (GENTILI, 2005).

Em consonância ao discurso hegemônico, o aperfeiçoamento do capital humano proporciona maiores condições de empregabilidade, o que por si só não é garantia de inserção no mercado,

[...] simplesmente, porque no mercado não há lugar para todos. "Empregabilidade" não significa, então, [...], garantia de integração, senão melhores condições de competição para sobreviver na luta pelos poucos empregos disponíveis: alguns sobreviverão, outros não". (GENTILI, 2005, p. 54).

Nessa mesma perspectiva, Alves (2007) sustenta que

A educação ou a aquisição (consumo) de novos saberes, competências e credenciais apenas habilitam o indivíduo para a competição num mercado de trabalho cada vez mais restrito, não garantindo, portanto, sua integração sistêmica plena (e permanente) à vida moderna. Enfim, a mera posse de novas qualificações não garante ao indivíduo um emprego no mundo do trabalho. (ALVES, 2007, p. 253).

A inculcação desse conceito escamoteia a lógica perversa e excludente do sistema capitalista, oculta a sua incapacidade de integrar um considerável contingente de trabalhadores à vida produtiva, perpetua um exército de reserva com vistas a intensificação da

\footnotetext{
1 Tal teoria considerava o conhecimento e as habilidades técnicas como um capital gerador de lucro e acumulação de riqueza, estabelecendo uma relação direta "entre produtividade, eficiência, desenvolvimento e riqueza capaz de explicar as diferenças de crescimento econômico entre países e empresas e de salários entre os indivíduos". (MARTINS; NEVES, 2010, p. 62).
} 
exploração da força de trabalho, assim como transfere ao indivíduo a responsabilidade pela sua qualificação e pelo sucesso e/ou fracasso de sua inserção profissional.

Ainda que não constitua como garantia de inserção no mercado de trabalho, a educação em geral e a educação superior, em particular, assumem centralidade. Esta,

[...] passa a ter como prioridades, a partir de então, capacitar a força de trabalho para adaptar a tecnologia produzida no exterior e conformar este novo trabalhador qualificado às novas exigências da cultura empresarial, especialmente no que tange à aceitação, como naturais, das desigualdades sociais, da competição acirrada entre indivíduos, grupos e classes e da perda dos seus direitos, conquistados ao longo da História. (NEVES; FERNANDES, 2002, p. 26).

Emerge, em uma perspectiva pragmática e utilitarista, um modelo de educação subordinado aos princípios da reestruturação produtiva, reconfigurando a educação superior brasileira ao atendimento das demandas do mercado. Esse processo de reconfiguração, pautado nos princípios da mercantilização, diversificação, descentralização e flexibilização, foi materializado com a promulgação da Lei de Diretrizes e Bases da Educação nº 9.394/96, "na qual o Estado assumiu papel destacado no controle e na gestão das políticas educacionais, ao mesmo tempo em que liberaliza a oferta da educação superior pela iniciativa privada" (CHAVES, 2010, p. 485).

Dessa forma, sob o ideário da flexibilização, o Estado brasileiro flexibilizou e oportunizou a mercantilização do sistema de ensino superior, com a abertura para o credenciamento de universidades, centros de educação superior, institutos, faculdades e escolas superiores; flexibilizou a estrutura e o funcionamento dos cursos, com a oferta de cursos de graduação, tecnológicos, sequenciais e à distância; e, flexibilizou o currículo.

A atenção voltada para o currículo justifica-se pelo fato de que

Para o governo, 'a inadequação dos currículos às carências e necessidades da população escolar, tendo em vista, principalmente, a formação de cidadãos conscientes e aptos a enfrentar as exigências da sociedade moderna', obstaculizava a consecução de seu programa de ação. Remover tal obstáculo era, então, 'condição imprescindível para melhorar a qualidade do ensino, reduzir a evasão escolar e combate as altas taxas de repetência'. (SHIROMA; MORAES; EVANGELISTA, 2007, p. 82).

Responsabilizado pelos altos índices de repetência e de evasão, a ênfase no currículo, fio condutor da formação acadêmica e "produto de tensões, conflitos e concessões culturais, políticas e econômicas" (APPLE, 2006, p. 59), escamoteia a verdadeira intencionalidade que é a adequação dos novos perfis profissionais às transformações ocorridas no mundo do trabalho. Ademais, tal centralidade negligencia outros aspectos que devem ser considerados 
para o alcance da melhoria na qualidade da educação, como as condições precárias das instituições de ensino públicas e o quantitativo insuficientes de professores.

Com o intuito de aproximar a Educação Superior e a formação profissional à lógica do mercado, as mudanças curriculares dos cursos de graduação foram engendradas com base na: “a) flexibilidade na organização curricular; b) dinamicidade do currículo; c) adaptação às demandas do trabalho; d) integração entre graduação e pós-graduação; e) ênfase na formação geral; f) definição de competências e habilidades gerais" (CATANI; OLIVEIRA, DOURADO, 2001, p. 74, grifos nossos).

Essa nova organização curricular, visando a expansão e a massificação da Educação Superior, aponta para o aligeiramento e a fragmentação da formação por meio da diminuição no tempo de integralização dos cursos, ora voltados para o desenvolvimento de competências técnicas e para a formação do trabalhador multifuncional, polivalente e flexível, em detrimento a uma formação humana, ética e política.

Cumpre elucidar a diferença entre os termos polivalência e politecnia, por tratar-se de um dos elementos centrais de nossa discussão, enquanto que

[...] por polivalência entende-se a ampliação da capacidade do trabalhador para aplicar novas tecnologias, sem que haja mudança qualitativa desta capacidade. Ou seja, para enfrentar o caráter dinâmico do desenvolvimento científico-tecnológico o trabalhador passa a desempenhar diferentes tarefas usando distintos conhecimentos, sem que isto signifique superar o caráter de parcialidade e fragmentação destas práticas ou compreender a totalidade. [...] A politecnia significa o domínio intelectual da técnica e a possibilidade de exercer trabalhos flexíveis, recompondo as tarefas de forma criativa; supõe a superação de um conhecimento meramente empírico e de formação apenas técnica, através de formas de pensamento mais abstratas, de crítica, de criação, exigindo autonomia intelectual e ética. (KUENZER, 2000, p. 86).

Nesse sentido, a polivalência implica na formação de um trabalhador acrítico e multitarefeiro, que se adapta rapidamente às demandas do mercado, e, em contrapartida, a formação politécnica pressupõe uma formação ampla, para além do pragmatismo preconizado pela formação polivalente. Assim sendo, com relação ao discurso hegemônico produzido pela política curricular, Catani, Oliveira e Dourado (2001) alertam que

[...] é preciso ter claro que a política oficial, ao se apropriar e redirecionar essa temática, em uma perspectiva pragmática e utilitarista de ajuste ao mercado, reduz a função social da educação superior ao ideário da preparação para o trabalho, a partir da 
redefinição de perfis profissionais baseados em habilidades e competências hipoteticamente requeridas pelo mercado em mutação. (CATANI; OLIVEIRA; DOURADO, 2001, p. 77).

Tal política está, portanto, visceralmente relacionada ao atendimento da lógica do mercado, na qual o mundo do trabalho determina o perfil do profissional necessário para o atendimento de suas demandas e as Universidades constituem-se em loci privilegiado de formação e desenvolvimento de habilidades e competências desses novos profissionais.

Por todo o exposto, fica evidente o novo perfil profissional exigido pela demanda do mercado assim como o processo de reconfiguração da Educação Superior, que se deu, dentre outros, sob o princípio da flexibilização, concedendo centralidade às mudanças curriculares.

\section{As DCN para os cursos de graduação em Engenharia: A materialização das mudanças curriculares}

As questões curriculares adquiriram centralidade na discussão educacional enquanto perspectiva norteadora da formação profissional em decorrência das "reformas" implementadas a partir dos anos 1990 no Brasil, já apontando uma aproximação entre o campo educacional e a esfera produtiva. Sobre essa questão, Sacristán (2000, p. 17) afirma que "[...] o sistema educativo serve a certos interesses concretos e eles se refletem no currículo [...]”, traduzindo-se em um conjunto de elementos teórico-pedagógicos que sofre determinações das mais variadas naturezas, sejam elas políticas, econômicas, ideológicas, culturais ou sociais.

Tal aspecto é nitidamente observado com a materialização e implantação de Diretrizes Curriculares nos diversos níveis da educação, em especial, das DCN dos cursos de graduação. O exórdio desse processo deu-se com a promulgação da Lei de Diretrizes e Bases da Educação Nacional (LDB) n. 9.394/96, que, em seu art. 53, inciso II, assegurou às universidades, no exercício de sua autonomia, "fixar os currículos dos seus cursos e programas, observadas as diretrizes gerais pertinentes" (BRASIL, 1996), e, foi consubstanciado com a aprovação das orientações gerais estabelecidas no Parecer CNE/CES n. 776/97, ao preconizar que as novas diretrizes devem

[...] promover no estudante a capacidade de desenvolvimento intelectual e profissional autônomo e permanente. Devem também pautar-se pela tendência de redução da duração da formação no nível de graduação. Devem ainda promover formas de aprendizagem que contribuam para reduzir a evasão, como a organização dos cursos em sistemas de módulos. 
Devem induzir a implementação de programas de iniciação científica nos quais o aluno desenvolva sua criatividade e análise crítica. Finalmente, devem incluir dimensões éticas e humanísticas, desenvolvendo no aluno atitudes e valores orientados para a cidadania. (BRASIL, 1997, p. 2, grifos nossos).

Neste excerto, percebemos uma intenção contraditória inerente ao discurso das DCN. Por um lado, fomenta a autonomia, a criatividade e o pensamento crítico do estudante. Por outro, determina o aligeiramento dos cursos de graduação. Ou seja, “[...] a despeito de indicar, por um lado, processos de autonomização na composição curricular, podem, por outro, ser compreendidas como mecanismos de ajuste e aligeiramento da formação" (CATANI; OLIVEIRA; DOURADO, 2001, p. 75). Além disso,

Os cursos de graduação precisam ser conduzidos, através das Diretrizes Curriculares, a abandonar as características de que muitas vezes se revestem, quais sejam as de atuarem como meros instrumentos de transmissão de conhecimento e informações, passando a orientar-se para oferecer uma sólida formação básica, preparando o futuro graduado para enfrentar os desafios das rápidas transformações da sociedade, do mercado de trabalho e das condições de exercício profissional. (BRASIL, 1997, p. 2, grifos nossos).

O referido dispositivo legal traz em seu bojo uma concepção de homem, de mundo e de educação enviesada aos princípios neoliberais. Não obstante, demonstrar preocupação com a superação da educação como mera transmissora de conhecimento, em sua essência volta-se para a formação e instrumentalização do perfil de um novo tipo de trabalhador, apto para adequar-se às demandas do mercado de trabalho.

Nesse contexto, a propalada modernização do ensino contempla o aligeiramento na formação e o "ideário da flexibilidade curricular e da sintonia com a vida e com a empregabilidade" (CATANI; OLIVEIRA; DOURADO, 2001, p. 72). No conjunto dos cursos de graduação, sob influência de iniciativas nacionais, tais como a LDB, o Programa de Reengenharia do Ensino das Engenharias (REENGE), o Edital n. 04/97 do MEC/SESu, o Fórum de Pró-Reitores de Graduação das Universidades Brasileiras (ForGRAD) e o Conselho Regional de Engenharia e Arquitetura (CREA) (SANTOS, 2009), a área de Engenharia também sofreu forte ingerência, com a instituição de suas DCN por meio da Resolução CNE/CES n. 11, de 11 de março de 2002.

Assim, ao analisar-se as DCN dos cursos de Engenharia, observa-se um alargamento do perfil profissional do engenheiro para o atendimento as demandas do mercado e da acumulação de capital, na medida em que, de acordo com o seu art. $3^{\circ}$, o perfil do egresso deve contemplar uma 
[...] formação generalista, humanista, crítica e reflexiva, capacitado a absorver e desenvolver novas tecnologias, estimulando a sua atuação crítica e criativa na identificação e resolução de problemas, considerando seus aspectos políticos, econômicos, sociais, ambientais e culturais, com visão ética e humanista, em atendimento às demandas da sociedade". (BRASIL, 2002, p. 1, grifos nossos).

Substituindo os currículos mínimos, considerados excessivamente rígidos e ineficazes para o alcance da qualidade, as DCN, em face das transformações no mundo do trabalho e suas implicações na Educação Superior, imprimiram maior flexibilidade ao currículo e por conseguinte, ao perfil profissional dos egressos em Engenharia, visto que,

Dos engenheiros do século XXI exige-se muito menos domínio do conteúdo de suas áreas de atuação e muito mais capacidade de: resolver problemas, tomar decisões, trabalhar em equipe e se comunicar. Isso é o que se entende por uma abordagem baseada na competência, formando na graduação profissionais capazes de enfrentar os desafios que o cenário atual a eles se impõe e que, portanto, tem na sua natureza intrínseca de profissionais competentes as características de serem: flexíveis, adaptáveis, criativos e críticos. (CORDEIRO; QUEIRÓS; BORGES, 2010, p. 126, grifos nossos).

Entretanto, não se deve confundir esse espirito de criticidade e criatividade com a "busca da transformação radical na realidade social, busca de superação radical da sociedade capitalista, mas sim criatividade de encontrar novas formas de ação que permitam melhor adaptação aos ditames da sociedade capitalista” (DUARTE, 2001, p. 38), posto que a essência desse modo de produção constitui-se na exploração e expropriação da criatividade e da produtividade do trabalhador na busca insaciável pela obtenção e maximização de lucros.

Assim, a formação preconizada na DCN reporta-se a promoção de um perfil "de engenheiro com capacidades de iniciativa e inovação, de resolver problemas relativos ao trabalho do engenheiro com eficiência e eficácia, e de adaptar-se ao processo de produção e reprodução do capitalismo" (RAMOS, 2014, p. 62).

No que tange a organização curricular, essa mesma Regulamentação prevê a divisão em três núcleos de conteúdos, sendo: um de conteúdos básicos; um destinado à caracterização da identidade do profissional; e, outro de conteúdos específicos que caracterizam a modalidade do curso. Entretanto, no conjunto de disciplinas de conhecimentos denominados básicos, chama a atenção a presença de vários componentes que não se voltam a uma visão humanista da sociedade, antes favorecem o desenvolvimento de habilidades práticas:

I - Metodologia Científica e Tecnológica; II - Comunicação e Expressão; III - Informática; IV - Expressão Gráfica; V - Matemática; VI - Física; VII - Fenômenos de Transporte; VIII - Mecânica dos Sólidos; IX - 
Eletricidade Aplicada; X - Química; XI - Ciência e Tecnologia dos Materiais; XII - Administração; XIII - Economia; XIV - Ciências do Ambiente; XV - Humanidades, Ciências Sociais e Cidadania. (BRASIL, 2002, p. 2, grifos nossos).

Como pode-se observar, representando apenas $30 \%$ da organização curricular, as disciplinas de formação básica favorecem o desenvolvimento de habilidades práticas e não dão conta de formar o egresso humanista preconizado pelas DCNEng. O que é acentuado no núcleo profissionalizante que contempla $15 \%$ da carga horária e não traz nenhuma referência a conteúdos que podem contribuir para a formação humanista, crítica e reflexiva, privilegiando a instrumentalização do futuro engenheiro.

Aprofundando os conteúdos do núcleo profissionalizante, o restante da carga horária total (55\%) da organização curricular dos cursos de Engenharia abrange o núcleo de conteúdos específicos, que “[...] constituem-se em conhecimentos científicos, tecnológicos e instrumentais necessários para a definição das modalidades e devem garantir o desenvolvimento das competências e habilidades estabelecidas nestas diretrizes" (BRASIL, 2002). Ou seja, de igual modo, não abordam questões que permitam problematizar e intervir junto a realidade social.

Dessa forma, face aos desígnios da reestruturação produtiva, da acumulação flexível e da flexibilização dos processos de trabalho, percebe-se que os princípios balizadores do discurso das DCNEng, pretendem "fabricar" determinado tipo de sujeitos, visto que há uma ênfase em conhecimentos técnicos, prevalecendo um caráter pragmático, não asseverando como parte da formação geral conhecimentos que levem à reflexão sobre os problemas sociais e perspectivas de mudança, questões pertinentes a um desenvolvimento omnilateral ${ }^{2}$ e comprometido com o desenvolvimento da sociedade.

\section{Considerações finais}

Diante do cenário da reestruturação produtiva, observa-se a consolidação da hegemonia do neoliberal e o enfraquecimento da educação e da classe trabalhadora, na medida em que vincula os processos formativos à sustentação da esfera produtiva capitalista, preconizando a valorização do conhecimento utilitarista e pragmático.

\footnotetext{
${ }^{2}$ Educação omnilateral designa “[...] a concepção de educação ou de formação humana que busca levar em conta todas as dimensões que constituem a especificidade do ser humano e as condições objetivas e subjetivas reais para seu pleno desenvolvimento histórico. [...]. Em síntese, educação omnilateral abrange a educação e a emancipação em todos os sentidos humanos [...]" (FRIGOTTO, 2012, p. 267).
} 
Nesse contexto, salienta-se também que a educação, em virtude de não ser um elemento neutro, acaba por expressar interesses de forças sociais, políticas e econômicas, estando inserido na lógica e nas determinações do capitalismo. Assim, a Educação Superior, cujo espírito de flexibilização espelha a sua interface com o mundo do trabalho, serve como pano de fundo para camuflar a exploração e a subordinação do trabalhador ao novo sistema de produção.

Do mesmo modo, infere-se que as DCN voltadas para os cursos de Engenharia contribuem para cimentar a matriz ideológica do neoliberalismo, tendo em vista que seus desenhos curriculares, apesar de assegurarem a formação de um profissional generalista, humanista, crítico e reflexivo, acabam por estabelecer estreito vínculo com o setor produtivo e por corroborar com a formação aligeirada e fragmentada de um trabalhador cada vez mais explorado e preparado para se adaptar a novas situações.

Não obstante a formação profissional configurar-se como uma das finalidades da Educação Superior, visto que a sociedade necessita de profissionais capacitados e o próprio ser humano precisa produzir suas condições materiais de existência, chama-se a atenção para o caráter eminentemente pragmático e utilitarista dessa formação e sua subsunção ao mundo de trabalho.

É, pois, necessário perceber o caráter contraditório da educação, em geral, e da Educação Superior, em particular, tanto como instrumento de produção e reprodução do grande capital quanto mecanismo de emancipação, buscando alternativas e possibilidades de mudanças no interior do sistema capitalista, com a consolidação de forças de resistências constituídas por meio de movimentos contra-hegemônicos, resgatando assim o princípio social da "educação para além do capital".

Ademais, é necessário construir um projeto de educação para a classe trabalhadora que permita evidenciar as contradições inerentes ao atual modelo de produção, contemplando, para além da formação técnica, uma formação omnilateral, abrangendo as dimensões ética, política, humanista e emancipatória.

\section{REFER̂̂ENCIAS}

ANTUNES, Ricardo. Os sentidos do trabalho: ensaio sobre a afirmação e a negação do trabalho. São Paulo: Boitempo, 2009. 
ALVES, Giovani. Dimensões da reestruturação produtiva: ensaios de sociologia do trabalho. Londrina: Praxis, 2007.

APPLE, Michael W. Ideologia e currículo. São Paulo: Brasiliense, 2006.

BEHRING, Elaine Rossetti. Brasil em contra-reforma: desestruturação do Estado e perda de direitos. São Paulo: Cortez, 2003.

BEHRING, Elaine Rossetti; BOSCHETTI, Ivanete. Política social: fundamentos e história. São Paulo: Cortez, 2008.

BIANCHETTI, Roberto G. Modelo neoliberal e políticas educacionais. São Paulo: Cortez Editora, 1997.

BRASIL. Ministério da Educação. Lei de Diretrizes e Bases da Educação Nacional - Lei n. 9.394/96, de 20 de dezembro de 1996. Estabelece as diretrizes e bases da educação nacional. MEC. Brasília, 1996.

BRASIL. Parecer CNE/CES n. 776/97, de 03 de dezembro de 1997. Orienta para as diretrizes curriculares dos cursos de graduação. MEC. Brasília, 1997. Disponível em:

$<$ http://portal.mec.gov.br/setec/arquivos/pdf_legislacao/superior/legisla_superior_parecer776 97.pdf $>$. Acesso em: 18 de jan. 2018.

BRASIL. Resolução CNE/CES n. 11/2002, de 11 de março de 2002. Diretrizes Curriculares Nacionais do Curso de Graduação em Engenharia. MEC. Brasília, 2002. Disponível em <http://portal.mec.gov.br/cne/arquivos/pdf/CES112002.pdf>. Acesso em: 18 de jan. 2018.

BURCH, Sally. Sociedade da Informação/Sociedade do Conhecimento. In: AMBROSI, Alain; PEUGEUOT, Valérie; PIMIENTA, Daniel (Coord.). Desafios de palavras: enfoques multiculturais sobre as sociedades da informação. [S. 1.]: C \& F Éditions, 2005.

CATANI, Afrânio Mendes; OLIVEIRA, João Ferreira de; DOURADO, Luiz Fernandes. Política educacional, mudanças no mundo do trabalho, e reforma curricular dos cursos de graduação no Brasil. Educação \& Sociedade, ano XXII, n. 75, p. 67-83, Agosto/2001.

CELLARD, André. Análise documental. In: POUPART, Jean et al. A pesquisa qualitativa: enfoques epistemológicos e metodológicos. Trad. Ana Cristina Nasser. Petrópolis, RJ: Vozes, 2012. p. 295-316.

CHAVES, Vera Lúcia Jacob. Expansão da privatização/mercantilização do ensino superior brasileiro: a formação de oligopólios. Educ. Soc., v. 31, n. 111, p. 481-500. Abr.-jun. 2010.

CORDEIRO, Joao Sergio; QUEIROS, Pedro Lopes; BORGES, Mario Neto. A Associação Brasileira de Educação em Engenharia. In: OLIVEIRA, Vanderli Fava de (Org.). Trajetória e estado da arte da formação em engenharia, arquitetura e agronomia. Brasília: Inep, Confea, 2010, p.21-54.

DUARTE, Newton. As pedagogias do "aprender a aprender" e algumas ilusões da assim chamada sociedade do conhecimento. Revista Brasileira de Educação, Set/Out/Nov/Dez., 
2001, n. 18. Disponível em: 〈http://www.scielo.br/pdf/rbedu/n18/n18a04>. Acesso em: 20 jan. 2018.

FRIGOTTO, Gaudêncio. Educação na crise do capitalismo real. São Paulo: Cortez, 2000.

FRIGOTTO, Gaudêncio. Educação omnilateral. In: CALDART, Roseli Salete et al (Org.). Dicionário da educação do campo. São Paulo: Escola Politécnica de Saúde Joaquim Venâncio, Expressão Popular, 2012.

GIL, Antônio Carlos. Métodos e técnicas de pesquisa social. 6. ed. São Paulo: Atlas, 2007.

GENTILI, Pablo. Três teses sobre a relação trabalho e educação em tempos liberais. In: SANFELICE, José Luís; SAVIANI, Dermeval; LOMBARDI, J. C. (Org.). Capitalismo, trabalho e educação. Campinas: Autores Associados, Histedbr, 2005, p. 45-59.

HARVEY, David. Condição pós-moderna: uma pesquisa sobre as origens da mudança cultural. São Paulo: Loyola, 1992.

KUENZER, Acácia Z. (Org.). Ensino médio: construindo uma proposta para os que vivem do trabalho. São Paulo: Cortez, 2000.

MARTINS, André Silva; NEVES, Lúcia Maria Wanderley. A nova pedagogia da hegemonia e a formação/atuação de seus intelectuais orgânicos. In: NEVES, Lúcia Maria Wanderley (Org.). Direita para o social e esquerda para o capital: intelectuais da nova pedagogia da hegemonia no Brasil. São Paulo: Xamã, 2010. p. 23-38.

MARX, Karl. O capital: crítica da economia política. Trad. Rubens Enderle. São Paulo: Boitempo, 2013.

MÉSZÁROS, Istvan. A crise estrutural do capital. Outubro - Revista do Instituto de Estudos Socialistas, Rio de Janeiro, n. 4, 2000. Disponível em: <http://outubrorevista.com.br/wpcontent/uploads/2015/02/Revista-Outubro-Edic\%CC\%A7a\%CC\%83o-4-Artigo-02.pdf $>$. Acesso em: 15 de fev. 2018.

NEVES, Lúcia Maria Wanderley; FERNANDES, Romildo Raposo. Política Neoliberal e Educação Superior. In: NEVES, Lucia Maria (org.). O empresariamento da educação: novos contornos do ensino superior no Brasil dos anos 1990. São Paulo: Xamã, 2002. p. 2140 .

NEVES, Lúcia Maria Wanderley; PRONKO, Marcela Alejandra. O mercado do conhecimento e o conhecimento para o mercado. Rio de Janeiro: EPSJV, 2008.

RAMOS, Adriana Regina. Educação e ensino nas produções científicas do Congresso Brasileiro de Educação em Engenharia: uma análise crítica sobre o ensino em Engenharia. 09/12/2014 172 f. Dissertação (Mestrado em Educação) - Universidade Estadual do Oeste do Paraná, Francisco Beltrão.

SACRISTÁN, José Gimeno. O currículo - uma reflexão sobre a prática. Porto Alegre: Artmed, 2000. 
SANTOS, Sara Rios Bambirra. O Projeto Político Pedagógico do Curso de Engenharia

Elétrica do CEFET-MG: das prescrições curriculares às discussões dos sujeitos da prática. 2009. Dissertação (Mestrado em Educação Tecnológica) - Centro Federal de Educação Tecnológica de Minas Gerais, Minas Gerais.

SHIROMA, Eneida Oto; MORAES, Maria Célia Marcondes de; EVANGELISTA, Olinda. Política Educacional. Rio de Janeiro: Lamparina, 2007.

\section{SOBRE AS AUTORAS:}

\section{Luciléa Santos Ayres da Silva}

Mestre em Educação, pela Universidade Federal do Amapá (UNIFAP); Técnica em Assuntos Educacional da UNIFAP - Brasil; Membro do Grupo de Estudo e Pesquisa Marxismo, Trabalho e educação (GEMTE). E-mail: leaayres@bol.com.br

iD http://orcid.org/0000-0003-0150-4078

\section{Arthane Menezes Figueirêdo}

Doutora em Educação, pela Universidade Federal de Uberlândia (UFU); Professora Adjunta da Universidade Federal do Amapá (UNIFAP) - Brasil; Docente permanente no Programa de Pós-Graduação em Educação da UNIFAP; Membro do Grupo de Estudo e Pesquisa Marxismo, Trabalho e Educação (GEMTE). Email: arthane@gmail.com

iD http://orcid.org/0000-0001-9124-5086 